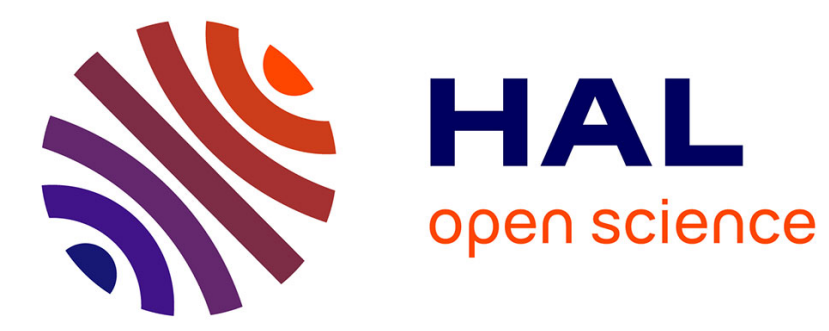

\title{
PRECIPITATION PROCESSES OF IMPLANTED IONS IN LiF
}

\author{
J. Davenas, A. Perez, C. Dupuy
}

\section{To cite this version:}

J. Davenas, A. Perez, C. Dupuy. PRECIPITATION PROCESSES OF IMPLANTED IONS IN LiF. Journal de Physique Colloques, 1976, 37 (C7), pp.C7-531-C7-535. 10.1051/jphyscol:19767120 . jpa00216843

\section{HAL Id: jpa-00216843 https://hal.science/jpa-00216843}

Submitted on 1 Jan 1976

HAL is a multi-disciplinary open access archive for the deposit and dissemination of scientific research documents, whether they are published or not. The documents may come from teaching and research institutions in France or abroad, or from public or private research centers.
L'archive ouverte pluridisciplinaire HAL, est destinée au dépôt et à la diffusion de documents scientifiques de niveau recherche, publiés ou non, émanant des établissements d'enseignement et de recherche français ou étrangers, des laboratoires publics ou privés. 


\title{
PRECIPITATION PROCESSES OF IMPLANTED IONS IN LiF
}

\author{
J. DAVENAS, A. PEREZ and C. DUPUY \\ Département de physique des matériaux, Université Claudz-Bernard Lyon I, \\ 43 boulevard du 11-Novembre-1918, 69621 Villeurbanne, France
}

\begin{abstract}
Résumé. - Des cristaux de LiF ont été bombardés avec des ions lithium, sodium et potassium à température ambiante et à basse température (température de l'azote liquide) et ont été étudiés par des techniques optiques. Nous avons pu observer à température ambiante la formation d'amas dus à la précipitation des ions implantés. Les bandes d'absorption qui leur sont associées $(520 \mathrm{~nm}$ pour le sodium et $700 \mathrm{~nm}$ pour le potassium dans $\mathrm{LiF}$ ) indiquent le caractère métallique de ces amas. A basse température ce processus est inhibé et le spectre d'absorption optique montre la croissance de nouvelles bandes d'absorption dans le proche infrarouge à $1000 \mathrm{~nm}$ pour le sodium $(1,24 \mathrm{eV})$ et $1400 \mathrm{~nm}$ pour le potassium $(0,9 \mathrm{eV})$. L'évolution du spectre d'absorption optique entre la température de l'azote liquide et la température ambiante indique une transformation partielle de ces bandes pour donner les bandes colloïdales associées aux précipités métalliques d'ions implantés. Nous montrons qu'à partir du modèle proposé dans la littérature pour des défauts associés aux ions alcalins dans des verres dopés et qui donnent des bandes d'absorption analogues, ces bandes peuvent être attribuées à des centres à électrons piégés formés sur de petits complexes alcalins d'ions implantés. Le processus d'agglomération resterait donc limité à basse température à la formation de petits aggrégats tandis que les ions alcalins précipiteraient à température ambiante dans une plus large mesure pour donner des particules colloïdales.
\end{abstract}

Abstract. - LiF crystals have been bombarded with lithium, sodium and potassium ions at room and low temperature (LNT) and have been studied by optical techniques. We could observe at room temperature the formation of clusters due to the precipitation of the implanted ions. The associated absorption bands $(520 \mathrm{~nm}$ for sodium and $700 \mathrm{~nm}$ for potassium in $\mathrm{LiF}$ ) indicate that these clusters have a metallic character. At low temperature this precipitation process is inhibited and the optical spectrum shows the growth of new absorption bands in the near infrared at $1000 \mathrm{~nm}$ for sodium $(1.24 \mathrm{eV})$ and $1400 \mathrm{~nm}$ for potassium $(0.9 \mathrm{eV})$. The evolution of the optical spectrum between low and room temperature indicates a partial transformation of these bands into the colloidal bands associated to the metallic precipitates of the implanted ions. According to the model proposed in literature for a class of defects associated to alkali ions in doped glasses that gives similar absorption bands, the bands at $1000 \mathrm{~nm}$ and $1400 \mathrm{~nm}$ may be attributed to trapped electron centres formed on small alkali complexes of the implanted ions. The agglomeration process would be then limited at low temperature to the formation of small aggregates whereas the alkali ions would precipitate at room temperature in a larger extend to give colloidal metallic particles.

1. Introduction. - The defects induced in alkali halides by irradiation have been extensively studied because of the large gap of such materials, that allows microscopic studies of the defects by optical technics or magnetic resonance spectroscopy. Most of the defects observed in irradiated LiF have been characterized but little is known about the implantation effects that occur simultaneously with the creation of defects during ion bombardement. The production of U-centres is one of the only cases known in literature to be related to the ion implantation process [1].

In a previous work [2] we have reported the growth of new absorption bands during thermal annealings of LiF crystals implanted with alkali ions $\left(\mathrm{Li}^{+}, \mathrm{Na}^{+}\right.$ and $\mathrm{K}^{+}$), the position of which depends on the nature of the implanted ions. The thermal properties of these bands indicated that they were of colloidal origin and could be attributed to implanted ion centres. It appeared during thermal annealings that the conditions in which these bands could be revealed were strongly dependent on the irradiation conditions. The purpose of this paper was then to investigate the influence of the most important parameters on the formation of the implanted ion centres. We choose to vary the irradiation temperature and the implanted ion dose and to use an ion flux sufficient to get reasonable irradiation times but not too important to avoid the local heating in the irradiated thickness of the sample, which is difficult to take into account and to control. These investigations have led us to observe new implantation effects and in particular the formation of new centres at low temperature that have been attributed to small aggregates of implanted ions.

2. Experimental procedure. - LiF single blocks were obtained from Quartz and Silice and prehardened by exposure to ${ }^{60} \mathrm{Co} y$-rays. The samples were then cleaved along a $(1,0,0)$ direction and annealed for 
several hours to remove the induced damage. The implantations $\left(\mathrm{Li}^{+}, \mathrm{Na}^{+}, \mathrm{K}^{+}\right.$) were performed using the Van de Graaf accelerator of the IN2P3 of Lyon at energies of the order of $500 \mathrm{keV}$. A special Van de Graaf terminal has been built by the Institut de Physique Nucléaire for solid sources that uses the thermoionic emission of lithium, sodium or potassium filaments. The analyzed beam of the accelerator was defocused over an area of about $1 \mathrm{~cm}^{2}$, with a particle flux of $6 \times 10^{12}$ ions $/ \mathrm{cm}^{2} \mathrm{~s}$ for $\mathrm{LiF}$ samples at energies lower than $1 \mathrm{MeV}$. For such a particle flux the $V_{b}$ band remains stable in LiF samples cooled at liquid nitrogen temperature, what shows that there is no local heating greater than $120 \mathrm{~K}$. The irradiations were performed at room or liquid nitrogen temperature in a chamber specially designed [3] to be placed into the sample compartment of a modified Beckman DK2A Spectrophotometer. The cryostat mounted on this chamber allowed an upper position of the samples hold on the cooled part of the cryostat for irradiation and a lower position for optical absorption measurements, so that it was possible to follow the evolution of the optical spectrum on the same sample for increasing implanted ion doses up to $2.5 \times 10^{17}$ ions $/ \mathrm{cm}^{2}$.

3. Room temperature irradiations. - The optical absorption spectrum of LiF samples bombarded with increasing ion doses up to $10^{16}$ ions $/ \mathrm{cm}^{2}$ presents only absorption bands due to the colour centres of the $F$ or F-aggregate centre type. We know that the formation of such defects is mainly related to excitation effects so that their distribution inside the crystal is closely related to the electronic energy losses of the bombarding particle [4]. The amplitude of such bands remains then limited at low energies and becomes lower for a same enregy when increasing the mass of the implanted ion. The optical absorption spectrum of LiF samples implanted with lithium, sodium or potassium ions does not present then any obvious effect that would be related to the implanted ions up to a dose of about $10^{16}$ ions $/ \mathrm{cm}^{2}$. As reported in a previous paper [2] new absorption bands due to the implanted ions themselves only appear during thermal annealings at $520 \mathrm{~nm}$ for sodium and $700 \mathrm{~nm}$ for potassium in $\mathrm{LiF}$. It had already been observed that at the opposite of additively coloured crystals the formation of the lithium colloidal band was relatively disconnected of the bleaching of the F-band. The evolution of the optical spectrum during thermal annealings shows that the absorption bands at $520 \mathrm{~nm}$ and $700 \mathrm{~nm}$ begin to appear when most of the colour centres have bleached and that their growth occurs with a partial transformation of the intrisic lithium colloidal band into these bands. In fact it may be observed that the lithium colloidal band known to be at $445 \mathrm{~nm}$ in LiF is anomalously broad and dissymetric on the large wavelength side for samples implanted with sodium or potassium what suggests us that in a first stage we have mixed colloidal agglomerates of lithium and implanted ions, that is followed by a second stage of segregation of the foreign ions under the form of precipitates of the implanted ions. During all this stage of precipitation we observe the growth of the corresponding colloidal band at a constant wavelength what is in good agreement with Doyle's theory [5] as long as the size of the precipitates remains small, and shifts towards larger wavelengths for bigger precipitates, what is observed for long thermal annealings. Figure 1 shows two typical spectra of

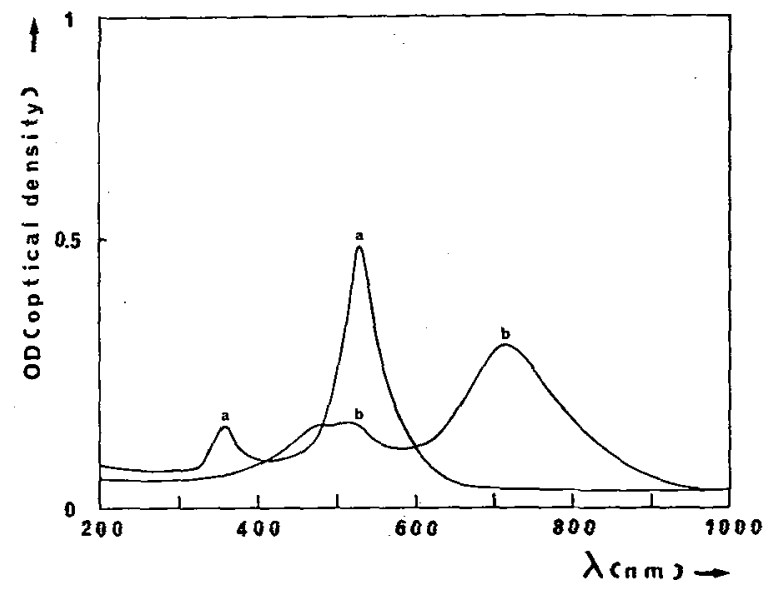

Fig. 1. - Optical absorption bands of thermally annealed LiF samples implanted with $10^{16}$ ions $/ \mathrm{cm}^{2}$ at the end of isochronous annealings of $105 \mathrm{mn}$ by steps of $20^{\circ} \mathrm{C}$ between $180^{\circ} \mathrm{C}$ and $420^{\circ} \mathrm{C}$ for sodium $(a)$ and between $180^{\circ} \mathrm{C}$ and $340^{\circ} \mathrm{C}$ for potassium $(b)$.

thermally annealed samples previously implanted with sodium (a) or potassium (b) ions. We observe in each spectrum that weak absorption bands are present on the short wavelength side of the bands at $520 \mathrm{~nm}$ and $700 \mathrm{~nm}$. Similar optical properties have been obtained in Marseille [6, 7] for sodium and potassium granular thin films studied optically and by electron microscopy in static ultravacuum. The Marseille's group attributed the weaker absorption bands to interband transitions of the metal.

Figure 2 shows the evolution of the spectrum of a same crystal versus the implanted ion dose for doses greater than $10^{16}$ potassium ions $/ \mathrm{cm}^{2}$ (curve 2 to 5 ). We see that the integrated area under the $F$ and $F_{2}$ absorption bands remains nearly constant (F-band at $250 \mathrm{~nm}$ and $F_{2}$-band at $450 \mathrm{~nm}$ in $\mathrm{LiF}$ ) with an important increase of the background due to the growth of a new absorption band at about $600 \mathrm{~nm}$. Concerning this band it may be observed that its amplitude is a linear function of the dose, what shows that an absorption band may be due to the implanted ions before any thermal annealing when the concentration of the associated defects has become large enough for the sensitivity of the optical measurements. At the first thermal annealing performed on such a sample we see the transformation of this absorption band into the previous band thermally revealed at $700 \mathrm{~nm}$ for samples implanted at lower doses. The absorption 


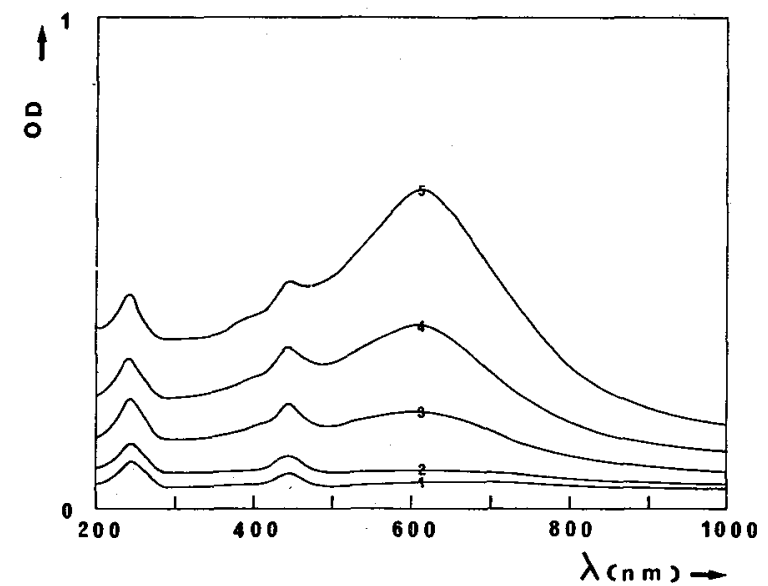

FIG. 2. - Optical absorption spectrum evolution of a LiF sample for increasing ion doses of potassium ions implanted at room temperature $\left(1: 10^{15}, 2: 6.6 \times 10^{15}, 3: 1.4 \times 10^{16}\right.$, $4: 2.9 \times 10^{16}, 5: 5.9 \times 10^{16} \mathrm{~K}^{+}$ions $\left./ \mathrm{cm}^{2}\right)$.

band observed at $600 \mathrm{~nm}$ is at an intermediate wavelength between the position of the lithium colloidal band at $445 \mathrm{~nm}$ and of the potassium colloidal band at $700 \mathrm{~nm}$. If we take into account the straggling of the bombarding particles in the stopping zone of the crystal we see that around each implanted ion there is a region of the crystal that has been perturbated many times by the overlapping of different displacement cascades. The previous assumption of the initial formation of mixed clusters of lithium and implanted ions seems then to be reasonnable, what would explain the presence of the corresponding absorption band at a lower wavelength than the expected one. The position of this band would depend then on two competeting processes : the increasing number of implanted ions and the increasing number of displaced atoms. Recombinations of the vacancy-interstitial pairs produced during the sequences of collisions would then appear in the optical spectrum by a shift of the band towards longer wavelengths.

Finally, if we consider the results obtained by the Marseille's group on alkali metal thin layers and the good aggreement between our observations with Doyle's theory, there is now a great evidence for the formation of precipitates of the implanted ions during irradiation at room temperature. High dose implantations show that an absorption band is related to these clusters due to the plasma oscillation of the free electrons of the metal and can be detected as soon as the sensitivity of optical measurements allows an unambiguous observation. The formation of such clusters has now been observed in other materials and in particular $\mathbf{P}$. Thévenard will report [8] the presence of colloidal bands of implanted ions in $\mathrm{MgO}$, which is a very convenient material for electronic microscopy.

4. Low temperature irradiations (LNT). - Figure 3 shows different optical spectra of a LiF sample obtained for increasing ion doses of potassium implanted

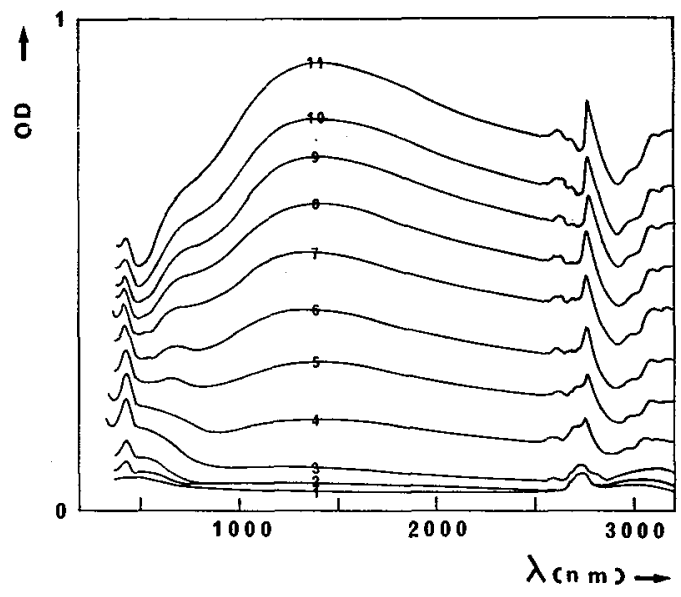

FIG. 3. - Optical absorption spectrum evolution of a LiF sample for increasing ion doses of potassium ions implanted at low temperature $\left(1: 10^{15}, 2: 6.6 \times 10^{15}, 3: 1.4 \times 10^{16}\right.$; $4: 2.9 \times 10^{16}, 5: 4.4 \times 10^{16}, 6: 5.9 \times 10^{16}, 7: 7.4 \times 10^{16}$, $8: 8.9 \times 10^{16}, 9: 1.04 \times 10^{17}, 10: 1.19 \times 10^{17}, 11:$ $1.34 \times 10^{17} \mathrm{~K}^{+}$ions $\left./ \mathrm{cm}^{2}\right)$.

ions at liquid nitrogen temperature. It may be noticed that there is only a slight increase of the optical absorption in the $600 \mathrm{~nm}$ region due to the growth of the previous absorption band (RT), what would indicate that the precipitation of the implanted ions into large clusters is inhibited at low temperature. At the opposite of the implantations performed at room temperature where the optical spectrum remained flat in the whole infrared we observe the growth of a new absorption band at $1400 \mathrm{~nm}$ for potassium ions. This band increases linearly with the number of implanted ions. In the case of sodium implanted samples the optical absorption measurements were perturbated by the superposition of oscillations due to interferences on the optical spectrum but a new band could therefore be resolved for high doses in the infrared with its maximum near $1000 \mathrm{~nm}$. Figure 4 shows the spectra associated to LiF samples implanted with $2.4 \times 10^{17} \mathrm{Na}^{+}(a)$ and $\mathrm{K}^{+}(b) / \mathrm{cm}^{2}$ and the compari-

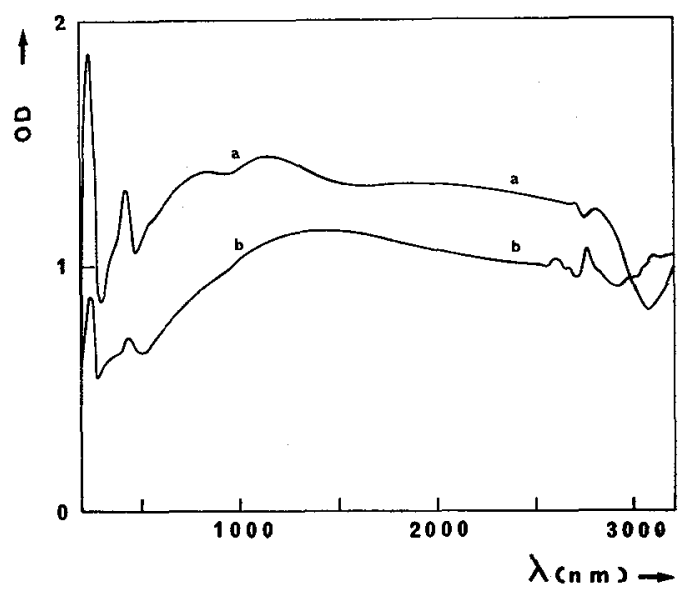

FiG. 4. - Absorption spectrum of LiF samples implanted with $2.4 \times 10^{17} \mathrm{Na}^{+}(a)$ and $\mathrm{K}^{+}$ions $/ \mathrm{t} \mathrm{cm}^{2}$ aLNT 
son in figure 5 of the two spectra plotted versus energy in $\mathrm{eV}$ illustrates the shift of the band associated to sodium towards higher energies. If we subtract the two weak absorption bands at $520 \mathrm{~nm}$ and $700 \mathrm{~nm}$ in each corresponding spectrum we obtain two bands centred on $0.9 \mathrm{eV}$ for potassium and $1.24 \mathrm{eV}$ for sodium. In the case of lithium implanted samples the optical spectrum remained flat from the red to the infrared but the presence of interferences was also noticed and we did not observed the growth of any anomalous band that would be related to the implanted ions.

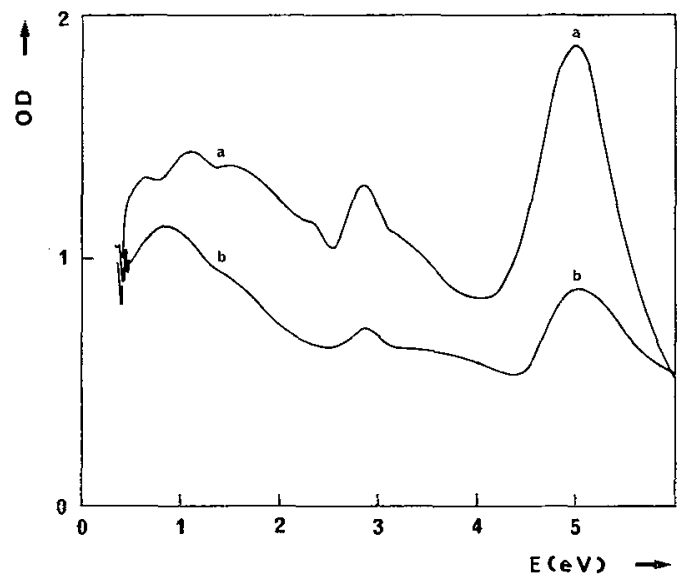

FIG. 5. - Absorption spectrum of LiF samples implanted with $2.4 \times 10^{17} \mathrm{Na}^{+}(a)$ and $\mathrm{K}^{+}$ions $/ \mathrm{cm}^{2}$ at $\mathrm{LNT}$ versus energy in eV.

New absorption bands are then observed in the optical spectrum of LiF samples implanted at low temperature with foreign alkali ions at $1000 \mathrm{~nm}$ for sodium and $1400 \mathrm{~nm}$ for potassium whereas the absorption bands formed at room temperature remain very weak. As agglomerates are produced at room temperature it seems a reasonnable assumption to suppose the formation of dispersed centres that would be responsible for the absorption bands at $1000 \mathrm{~nm}$ and $1400 \mathrm{~nm}$. Such an assumption was confirmed by the partial transformation of these bands into the colloidal bands of the implanted ions when the samples were warmed up to room temperature. Such a transformation takes place near room temperature and it is possible to observe the existence of a constant optical density point between the two bands.

A model may be suggested for these centres by the literature. As centres of the $F_{A}$ type have never been observed in the implanted crystals we may think to interstitial type centres. In the past history of colour centres there was always some controversies about the defects that eventually would be observed in the cationic sublattice. At present it appears that ionizing radiations produce defects in the anionic sublattice by excitation mechanisms but there is some evidence that the cationic sublattice is also concerned when using more energetic coloration modes like neutron or ion bombardment. In particular Farge has observed [9] an absorption band at $550 \mathrm{~nm}$ in neutron irradiated $\mathrm{LiF}$ that was attributed to lithium interstitials. These defects called I-centres have the structure of a $\mathrm{Li}_{2}^{+}$ molecular ion at the place of a normal lithium ion of the lattice and their formation may be interpreted by a direct displacement of a lithium ion into an interstitial position during a collision sequence. The I-centres are also not stable at room temperature. It may be noticed that we have to assume the trapping of electrons on these centres to give the proposed structure. There are quite different materials in which similar trapped-electron centres have been observed. It is the case of X-irradiated alkali borate glasses at $77 \mathrm{~K}$ where Griscom [10] has shown that a number of electrons were trapped on alkali ions or complexes of alkali ions. Certain of these centres may be responsible for an absorption band in the range 1-2 eV. Most of the arguments for such centres were given by ESR studies. The ESR spectra of sodium and potassium alkali borate glasses may be interpreted by defects involving unpaired electronic spins localized in potassium or sodium s-state atomic orbitals. Several attemps to fit the alkali dependent portions of the ESR spectra were performed with different molecular ions of the $\mathrm{K}_{2}^{+}, \mathrm{K}_{3}^{2+}, \mathrm{K}_{4}^{3+} \ldots$ type. It appears that the number of atoms involved in the alkali centres increases in the sequence $\mathrm{K}, \mathrm{Na}, \mathrm{Li}$ from $\mathrm{K}$ to $\mathrm{Li}$, what would be interpreted by the easiness of small atoms to diffuse and give larger aggregates. It may be recalled that the molecular ion structure is very common for colour centres of the interstitial type. Such a model seems then to be reasonnable for the defects associated to the bands at $1000 \mathrm{~nm}$ and $1400 \mathrm{~nm}$. Of course we may expect in the future to get from ESR studies some informations on the more probable structure for the alkali centres in LiF. However we think that according to the clear optical spectra obtained for implanted $\mathrm{LiF}$ samples the number of involved species must be limited to the simpler ones.

5. Conclusion. - It results from this study that alkali implanted ions have a tendency to cluster in LiF. At low temperature the agglomeration begins to occur after the trapping of electrons on small alkali complexes and remains limited to small aggregates. These aggregates have the configuration of molecular ions of the $\mathrm{K}_{2}^{+}, \mathrm{K}_{3}^{2+}, \mathrm{K}_{4}^{3+} \ldots$ type. Some of these species may be responsible for the absorption bands observed near $1000 \mathrm{~nm}$ for sodium and $1400 \mathrm{~nm}$ for potassium in LiF. The agglomeration process goes on in a larger extend near room temperature to give precipitates involving enough implanted ions to observe plasma oscillations of the alkali metal. At room temperature precipitates of the implanted ions are directly produced. The present study has shown that absorption bands were associated to aggregates corresponding to the different stages of the implanted ion precipitation. Using the evolution of the optical spectrum it was possible to follow the evolution of the defects. It 
appears then that the optical properties are a very direct way for the characterization of implanted alkali halides and may be very useful for the monitoring of the implantion itself.

\section{References}

[1] Hughes, A. E. and Pooley, D., J. Phys. C: Solid state Phys. 4 (1971) 1963.

[2] Davenas, J., Perez, A., Thévenard, P. and Dupuy, C., Phys. Status Solidi (a) 19 (1973) 679.

[3] Thévenard, P., Guiraud, G., Dupuy, C. and DelauNAY, B., Rad. Effects, to be published.

[4] Perez, A., Davenas, J. and DupuY, C., Nucl. Instr. Meth. 132 (1976) 219
[5] Doyle, W. T., Phys. Rev. 111 (1958) 1067.

[6] Payan, J. C. et Roux, D., Opt. Commun. 7 (1973) 26.

[7] Payan, J. C. et Roux, D., Opt. Commun. 11 (1974) 182.

[8] Thévenard, P., J. Physique Colloq. 37 (1976) C7, this issue.

[9] Farge, Y., Lambert, M. et Guinier, A., J. Phys. Chem. Solids 27 (1966) 499.

[10] Griscom, D., J. non-cryst. Solids 6 (1971) 275.

\section{DISCUSSION}

K. RöSSLER. - What is the number of implanted ions and does it have any influence - via overlap of the collision cascades formed - on the agglomeration of the alkali atoms?

J. Davenas. - In these experiments we implanted $10^{15}$ to $2.4 \times 10^{17}$ ions in a layer of about $1000 \AA$ $\left(500 \mathrm{keV} \mathrm{K} \mathrm{K}^{+}\right.$ions in $\left.\mathrm{LiF}\right)$. We observed a linear growth of the absorption bands associated to the small aggregates produced at LNT or to the larger agglomerates produced at room temperature so that these macroscopic results do not indicate any saturation effect that would be attributed to the overlapping of collision cascades. 